\title{
Wear of knee prostheses
}

This article was published in the following Dove Press journal:

Orthopedic Research and Reviews

3 April 2012

Number of times this article has been viewed

\section{Claire L Brockett \\ Louise M Jennings John Fisher}

Institute of Medical and Biological Engineering, School of Mechanical Engineering, University of Leeds, Leeds, UK
Correspondence: Claire L Brockett Institute of Medical and Biological Engineering, School of Mechanical Engineering, University of Leeds, Leeds, LS29 JT, UK

Tel +44 I I 33437472

Fax +44 II 324246 I I

Email c.l.brockett@leeds.ac.uk
Abstract: This paper describes how three different unique design solutions for artificial knee joints each provide extremely low wear and the potential for a 50-year osteolysis-free lifetime in high-demand patients. Each of the three low-wearing prosthetic design solutions provides a different and distinctive functional solution for the patient and surgeon.

Keywords: artificial knee joint, prostheses, wear

\section{Introduction}

Low-wearing solutions are needed to provide long-term function and survival of knee prostheses in young and active patients, in order to avoid failure as a result of polyethylene wear debris-induced osteolysis. ${ }^{1,2}$ This paper describes the latest understanding of the tribology and wear of polyethylene in knee joint replacements and is based on research carried out over the last decade. In particular, it describes new scientific findings and knowledge about the different variables that control degradation and wear of polyethylene in the knee and that contribute to failure of knee prostheses. It focuses on the needs of high-demand patients with long life expectancies, such as active patients in their early $50 \mathrm{~s}$, who walk or run up to two million steps every year, ${ }^{3}$ and who may have life expectancies of "fifty active years after fifty", and a lifetime functional demand of up to 100 million steps. Studies show the number and proportion of these high-demand patients are increasing and predicted to increase further. ${ }^{4}$ This paper describes how current scientific understanding of wear mechanisms has been used to develop new technological design solutions, with new materials and new design concepts, which generate lower wear and the potential of longer-lasting prostheses. The paper differentiates between fatigue failure and surface wear, and with the advent of stabilized and fatigue-resistant polyethylene, proposes that surface wear and osteolysis is the primary cause of long-term osteolysis and failure, most importantly because the surface wear of polyethylene is dependent on a number of different and independent variables. The paper describes how wear can be reduced by different mechanisms and design approaches, which result in three different and distinctive low-wear design solutions, each addressing the functional requirements of different surgeons and patients. This provides the basis for the first ever strategically and scientifically stratified product portfolio of low-wearing knee prostheses.

The paper is divided into six sections. The first two sections describe the science of polyethylene wear in the knee and the effect of surface wear and wear debris-induced osteolysis and failure. In particular, it stratifies the different types of wear and describes submit your manuscript | www.dovepress.com

Dovepress

http://dx.doi.org/10.2147/ORR.S28660
Orthopedic Research and Reviews 2012:4 19-26

(C) 2012 Brockett et al, publisher and licensee Dove Medical Press Ltd. This is an Open Access article which permits unrestricted noncommercial use, provided the original work is properly cited. 
the system variables which control wear. This provides insight into, and a better understanding of, the complex relationships between prosthesis design variables and wear-induced failure mechanisms. The concept of the total critical wear volume and the osteolysis threshold is introduced, and this shows that if a wear rate is less than $5 \mathrm{~mm}^{3} /$ million cycles then it can take over 50 years of wear to reach the threshold for osteolysis in the most active patient. The next three sections describe how wear can be reduced in three different ways, so producing three distinctive low-wear design solutions, which can provide up to "fifty active years after fifty" wear life. The third section describes the rotating platform mobile-bearing knee, low-wear solution, with low wear produced by the decoupling of complex motions into two linear motions resulting in low cross-shear. The fourth section describes the low-wearing fixed-bearing knee solution which utilizes moderately cross-linked polyethylene to give reduced surface wear. This also has a smooth tray and improved locking mechanism to reduce backside wear. The fifth section, describes the low conforming partial knee solution, a fixed-bearing knee with moderately cross-linked polyethylene, which has extremely low wear, associated with the low surface area being worn. The final section provides a summary of the scientific findings relating to knee replacement wear.

\section{Science of polyethylene wear}

This section describes the science of polyethylene wear, differentiating between the two fundamental wear mechanisms, ie, delamination and fatigue wear and surface wear.

Delamination and fatigue wear are dependent on the fatigue strength and toughness of the polyethylene, with a greater incidence of occurrence in historical gamma in air sterilized polyethylene, where the mechanical properties have deteriorated over time due to oxidative degradation. ${ }^{5,6}$ An example of delamination and fatigue failure is shown in Figure 1. The current generation of polyethylene, either polyethylene sterilized in an inert atmosphere or cross-linked polyethylene which is remelted, have higher levels of stability and are more resistant to oxidative degradation, and have a much lower incidence of delamination and fatigue failure. ${ }^{7,8}$ Delamination and structural fatigue has largely been eliminated in modern materials and designs and is no longer a clinical concern.

There is also an increased incidence of delamination and fatigue when contact stresses are higher. Traditional designs with historical gamma in air polyethylene moved to more conforming designs, with lower stresses to reduce the incidence of delamination. ${ }^{9-11}$ Such an example was the highly conforming low contact stress rotating mobile-bearing platform (DePuy Inc, Warsaw, IN). ${ }^{12}$

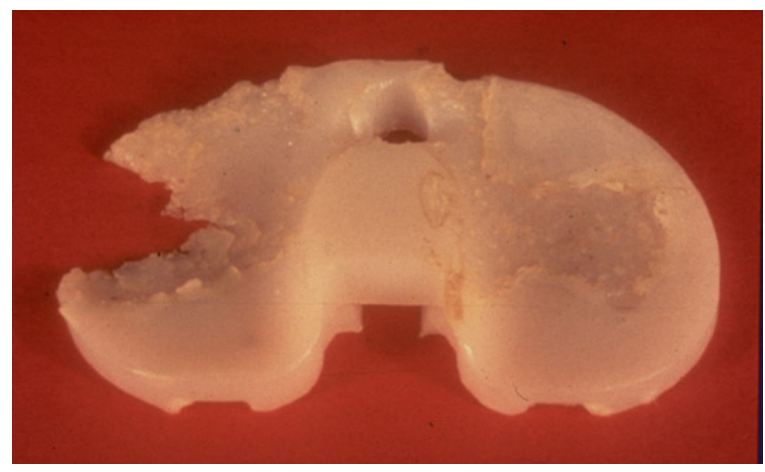

Figure I An example of delamination in knee with historical gamma in air polyethylene.

With the introduction of modern stabilized polyethylene materials, the mechanical properties of which do not deteriorate with time, ${ }^{13}$ it is possible to consider design solutions with a wider range of operating contact stresses, and still avoid delamination and fatigue wear. This can provide other advantages in performance. Although historically, with gamma in air sterilized polyethylene, more conforming designs were introduced to reduce the level of contact stresses and risk of delamination fatigue failure, ${ }^{11}$ this had only limited benefit, because high stresses could still occur due to misalignment or edge loading, which resulted in failure. Currently used stabilized polyethylenes provide a much better solution to reduce the risk of delamination fatigue, because these materials can withstand higher stress levels. ${ }^{14}$ With the current generation of stabilized polyethylenes that do not degrade, the potential risk of delamination fatigue wear is greatly reduced.

The major concern with current knee joint replacements is surface wear, the generation of submicron wear particles, their accumulation in periprosthetic tissues, and the subsequent resulting wear debris-induced osteolysis and loosening. ${ }^{1,2}$ The risk of wear debris-induced osteolysis can be reduced or delayed by reducing the surface wear rate of polyethylene in the knee and hence reducing the rate of accumulation of wear debris in tissues surrounding the prostheses. Surface wear is a complex engineering process, which is dependent on a number of independent variables, and is not simply a material property.

In considering improved design solutions for polyethylene in the knee, we have modified Archards law ${ }^{15}$ and introduced a new wear equation for polyethylene: ${ }^{16,17}$

$$
\begin{aligned}
\text { wear volume }= & \mathrm{C} \times(\text { sliding distance }) \\
& \times(\text { contact area }) \mathrm{f}(\text { cross-shear }) \\
& \times \mathrm{f}(\text { counter face roughness }) \\
& \times \mathrm{f}(\text { level of cross-linking })
\end{aligned}
$$


In particular, we have shown the wear rate is dependent on and reduces with reduced contact area, reduced crossshear, reduced surface roughness, and increased crosslinking. The primary relationship shows that the surface wear volume increases as the area of polyethylene being worn increases. ${ }^{16-20}$

The wear rate of polyethylene increases with an increase in cross-shear. ${ }^{21,22}$ At low cross-shear, associated with unidirectional motion, the wear rate is low; however, as cross-shear ratio increases to between 0.05 and 0.1 the wear rate reaches its maximum value. This is demonstrated for two different contact stress/contact area conditions in Figure 2. ${ }^{20,22}$

In the hip, where kinematics produce higher levels of cross-shear $>0.1$, an increase in the level of cross-linking in the polyethylene reduces the wear rate (Figure 3). However, at a higher level of cross-linking, mechanical properties of the polyethylene are reduced; cross-linking levels of 7.5 and $10 \mathrm{mRad}$ are too high to use in the knee..$^{23}$

In summary, delamination and fatigue wear can be eliminated by using currently manufactured stabilized polyethylene. The current major concern relates to surface wear and risk of wear debris-induced osteolysis, loosening, and failure of the prostheses. New knowledge on wear of polyethylene materials has defined a new wear law, where wear rate can be reduced by reducing cross-shear and wear area, and by increasing cross-linking, thus producing design solutions with lower wear rates and longer osteolysis-free lifetimes.

\section{Surface wear and threshold for osteolysis}

Surface wear of polyethylene and the potential of wear debris-induced osteolysis in the longer term is now becoming a major concern in the knee, as it has been in the hip for over a decade. ${ }^{24}$ The response to polyethylene debris varies from patient to patient, due to variation in individual patient

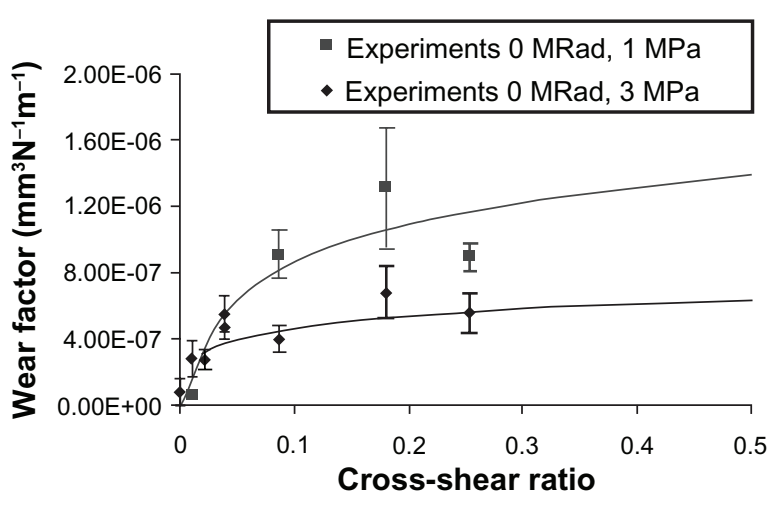

Figure 2 Increase in wear rate with increased cross-shear.

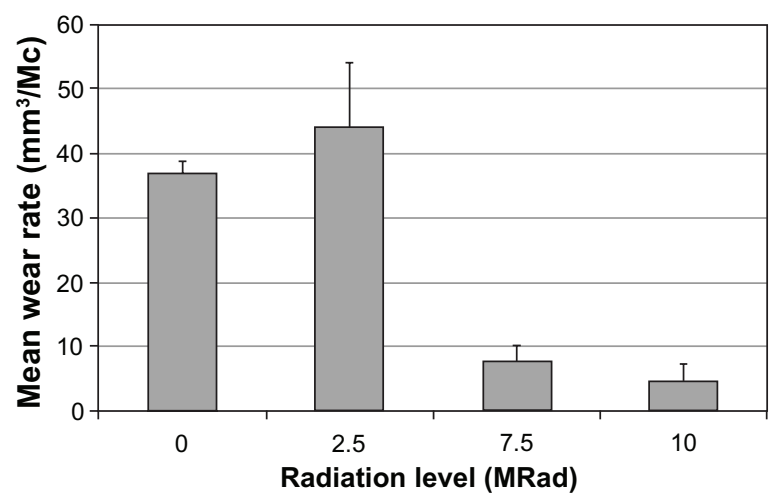

Figure $3 \mathrm{~A}$ reduction in wear rate in hip simulator with increased cross-linking. ${ }^{23}$

responsiveness. ${ }^{1}$ Additionally, variations in design, fixation interfaces, and access of polyethylene debris to tissue interfaces produces variability in patient response. However, there is a pattern in the hip that, on average, osteolysis and loosening occurs when the accumulation of total wear volume of standard polyethylene reaches approximately $500 \mathrm{~mm} .{ }^{3,25}$ Clearly local osteolysis can occur at much lower volumes of wear. The concept of a total volume wear as a threshold for osteolysis has been demonstrated in a number of papers ${ }^{2,25}$ on the hip and can be applied in the knee, where the rate of wear, and rate of accumulation of debris in periprosthetic tissues, is dependent on activity levels and number of steps per year, as well as kinematic demand.

Polyethylene surface wear debris in the knee is predominantly submicron in size and, like the hip, has a high potential to cause osteolysis. ${ }^{26}$ Analysis of the debris in retrieved tissues surrounding explanted hip prostheses shows increased volumetric concentration in tissues surrounding the hips with lifetimes greater than ten years than for retrievals of less than ten years, clearly demonstrating buildup of debris in the periprosthetic tissue over time. ${ }^{27}$ Analysis of tissue from knees retrieved after less than ten years shows similar levels to that found in early hip tissues at an equivalent time. ${ }^{27}$ Thus, the expectation is that the osteolytic threshold in the knee will be reached as in the hip, but the time taken to reach this is dependent on the rate of generation of debris. In fixed-bearing knees, the rate of wear is dependent on kinematic demand (level of cross-shear). Because the polymer insert in fixed-bearing knees cannot move relative to the tray, rotation of the knee occurs at the articulation between the femoral component and the tibial bearing component. Anterior-posterior translation also occurs at this articulation, as does flexion-extension. The rotation causes a multidirectional wear path which increases the cross-shear and thus wear rate (Figure 4). ${ }^{21}$ 


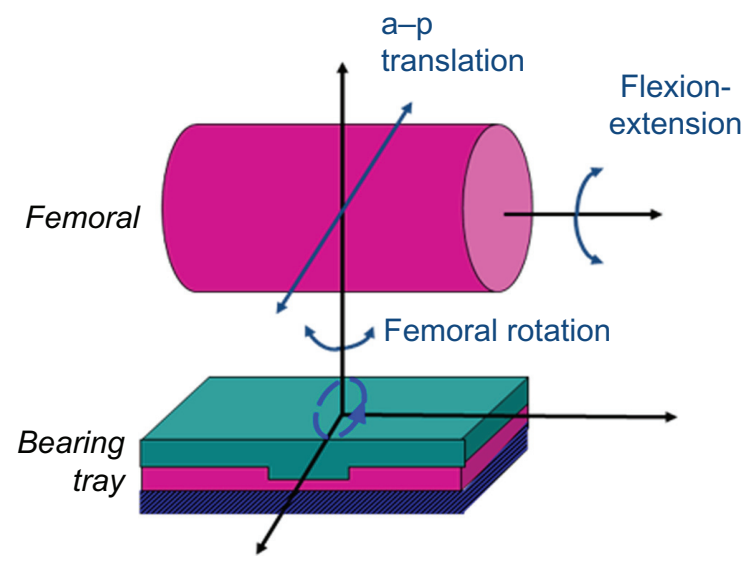

Figure 4 Complex cross-shear motion on superior surface of fixed-bearing knee.

In a displacement controlled knee simulator, the effect of different kinematic demands on wear can be studied in the conventional fixed-bearing knee, in this case the PFC Sigma ${ }^{\circledR}$ knee with gamma vacuum foil polyethylene and a fixed insert (DePuy International) ${ }^{21}$ Kinematic demand was increased by initially doubling internal-external rotation, then doubling the anterior-posterior translation and recording the effect on surface wear (Table 1). As the kinematic demand increased, the surface wear increased. Increasing rotation increased cross-shear and wear rate. ${ }^{16,21}$ An increase in anterior-posterior displacement increased the surface area exposed to increased cross-shear, again increasing surface wear (Figure 5).

For a conventional fixed-bearing knee, a high-demand patient with two million steps per year, high kinematic demand, and a polyethylene wear rate of $40 \mathrm{~mm}^{3} /$ year, can reach the osteolytic threshold of $500 \mathrm{~mm}^{3}$ in 12 years. In contrast, a low-demand patient with only moderate activity, one million steps/year, and moderate kinematic demand, may have a wear rate of less than $10 \mathrm{~mm}^{3} /$ year, and in this low-demand case, an existing conventional fixed-bearing knee is likely to last more than 50 years. This is supported by data from the Swedish hip registry where survivorship is lower in young and active patients, with wear and osteolysis being the major cause of failure..$^{28}$

Conventional fixed-bearing knees do not have sufficiently low wear rates to give an extended osteolysis-free lifetime in young and active patients with a life expectancy of up to

Table I Kinematic conditions for wear simulation studies

\begin{tabular}{llll}
\hline & $\begin{array}{l}\text { High } \\
\text { kinematics }\end{array}$ & $\begin{array}{l}\text { Intermediate } \\
\text { kinematics }\end{array}$ & $\begin{array}{l}\text { Low } \\
\text { kinematics }\end{array}$ \\
\hline AP displacement & $10 \mathrm{~mm}$ & $5 \mathrm{~mm}$ & $5 \mathrm{~mm}$ \\
IE rotation & $\pm 5^{\circ}$ & $\pm 5^{\circ}$ & $\pm 2.5^{\circ}$ \\
\hline
\end{tabular}

Abbreviations: AP, anterior-posterior; IE, internal-external.

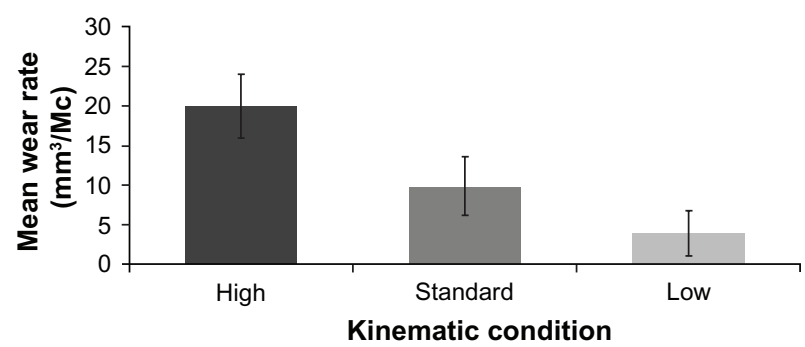

Figure 5 Increase in surface wear in fixed-bearing knee with increased kinematic demand and increased cross-shear.

50 years. Alternative low-wearing solutions are required. Because polyethylene wear is dependent on a number of independent variables, it is possible to generate different and distinctive low-wear solutions.

\section{Rotating platform mobile-bearing knee}

The rotating platform mobile-bearing knee provides one design solution for low surface wear by reducing the crossshear on polyethylene at the articulating surfaces. The design uniquely decouples the complex motions into two more linear motions on separate articulating interfaces.

In the rotating platform mobile-bearing knee, flexionextension and anterior-posterior translation occurs at the upper femoral interface. This is a linear low cross-shear motion. Rotation occurs at the lower tibial interface, as a curvilinear sliding motion, around the central peg. This is also a low cross-shear motion (Figure 6). ${ }^{21}$ Investigation of wear in the knee simulator shows a five-fold reduction in wear rate with the PFC Sigma rotating platform mobile-bearing knee compared with the PFC Sigma fixed-bearing knee with a curved insert, both with gamma vacuum foil polyethylene (DePuy International, Figure 7). ${ }^{21}$

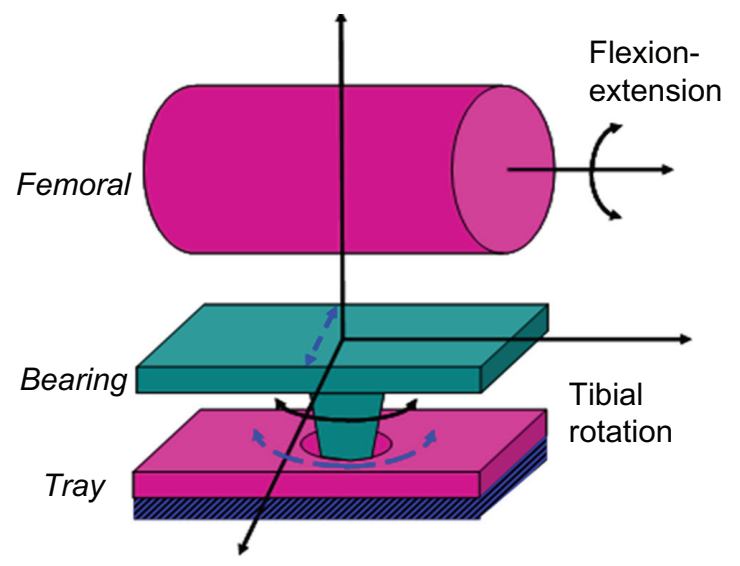

Figure 6 Decoupled motions with low cross shear on the upper and lower surfaces of the rotating platform bearing. 


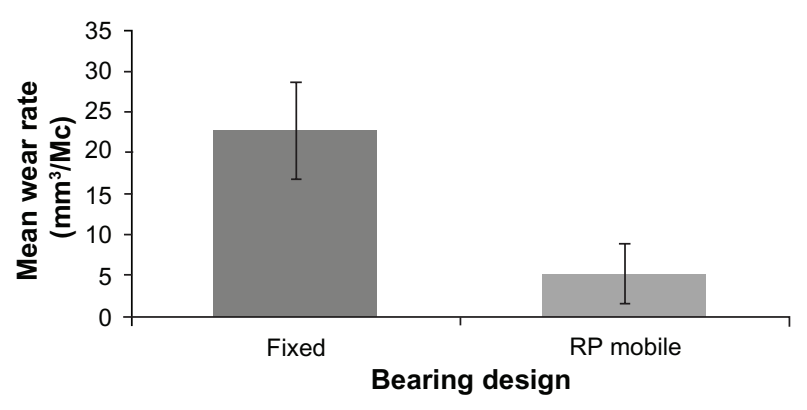

Figure 7 Reduction in wear in the PFC Sigma rotating platform knee compared with fixed-bearing knee with GVF polyethylene.

Abbreviations: RP, rotating platform; GVF, gamma vacuum foil.

Reduction in wear and cross-shear only occurs with the rotating platform mobile-bearing knee. Other mobilebearing knees have cross-shear motion on the lower surface and high wear. The rotating platform is the only knee design using conventional gamma vacuum foil polyethylene, which has a wear rate of less than $5 \mathrm{~mm}^{3} /$ million cycles and a predicted osteolysis free life of 50 years in high-demand patients. All knee designs require stability and soft tissue balance to ensure good function. In the rotating platform mobile-bearing knee, incorrect soft tissue tension, instability, and lift-off can cause an increase in the surface wear rate of the polyethylene, due to cross-shear introduced by the lateral shift during lift-off. ${ }^{29}$ In order to reduce wear in fixed-bearing knees, it is necessary to consider alternative design approaches.

\section{Low-wearing fixed-bearing knee}

For a conventional fixed-bearing knee (such as PFC Sigma) with high kinematic demand, the wear rate is $20 \mathrm{~mm}^{3} / \mathrm{million}$ cycles. For a high-demand patient with two million steps per year and high kinematic demand, the polyethylene surface wear rate is $40 \mathrm{~mm}^{3} /$ year and the osteolytic threshold of $500 \mathrm{~mm}^{3}$ can be reached in 12 years. It has been shown that about $30 \%$ of the wear is associated with the back side on the fixed tray, ${ }^{21}$ with the remainder on the upper articulating surface. In order to reduce surface wear, two approaches are needed, ie, a reduction in backside wear with use of a smooth tray and improved locking mechanism and introduction of medium cross-linked polyethylene.

The Sigma fixed-bearing knee (DePuy International) has been improved with the introduction of a smooth cobalt chrome tray and an improved locking mechanism. A smooth cobalt chrome tray and an improved locking mechanism in the new Sigma knee reduced the wear by $30 \%$ compared with the PFC Sigma knee with a rough titanium tray, in knee joint simulator tests with gamma vacuum foil polyethylene as the insert material (Figure 8). ${ }^{30}$

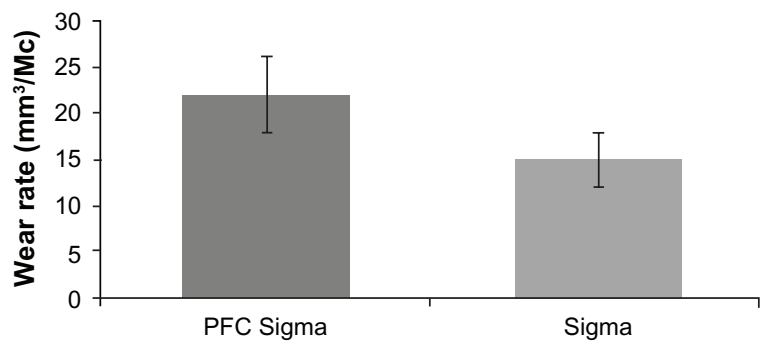

Figure 8 Reduction in backside wear with Sigma knee with smooth cobalt chrome tray and improved locking mechanism, under high kinematic demand, with gamma vacuum foil polyethylene.

However, a wear rate of $15 \mathrm{~mm}^{3} /$ million cycles ${ }^{30}$ only gives an osteolysis-free lifetime of 17 years in a high-demand patient. Therefore, in the Sigma knee, it is important to consider the use of cross-linked polyethylene to reduce surface wear further.

XLK (DePuy International) cross-linked polyethylene uses GUR1020 resin to give increased toughness, and is moderately cross-linked in order to retain mechanical properties. Following irradiation cross-linking, the polyethylene is remelted to remove free radicals and stabilize the material, and is then surface-sterilized to retain stability. In the Sigma knee with curved inserts, XLK polyethylene reduced the surface wear compared with gamma vacuum foil polyethylene by more than $50 \%$ under both intermediate and high kinematic demand ${ }^{31}$ (Figure 9). For XLK polyethylene, the surface wear with Sigma knee was between 3 and $6 \mathrm{~mm}^{3} /$ million cycles.

This substantial reduction in wear with XLK in Sigma fixed-bearing knees provides a second low-wear design solution with an extended osteolysis-free lifetime for a highdemand patient. This option will give predicted osteolysisfree lifetimes in excess of 40 years.

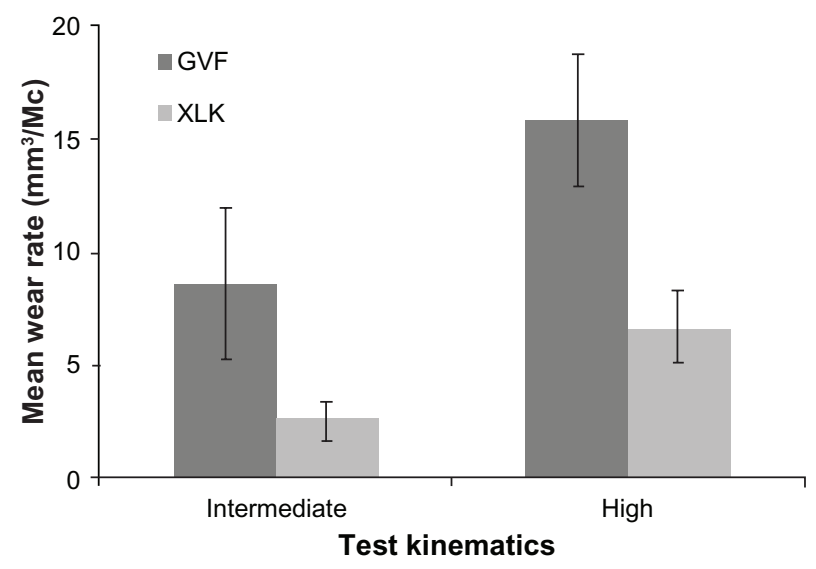

Figure 9 Reduction in wear by more than $50 \%$ with use of XLK polyethylene in the Sigma knee. 


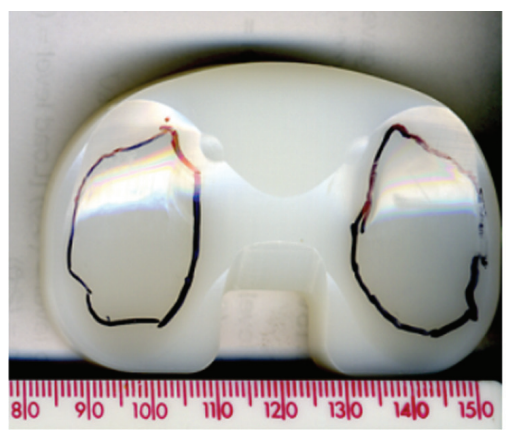

Curved insert

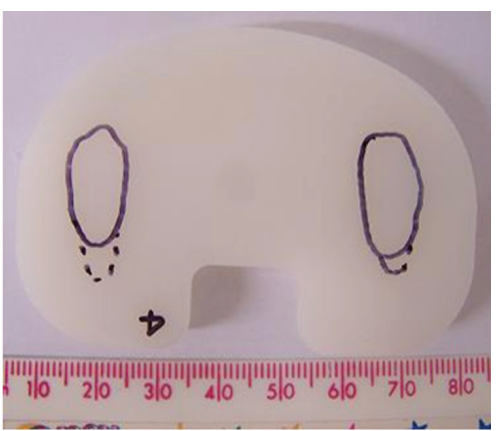

Flat insert

Figure 10 The surface area being worn on a curved insert and a flat insert in the Sigma knee.

\section{Low-conforming, low-wearing partial knee replacement}

Basic science has also demonstrated that polyethylene wear is dependent on the surface area being worn. For patients with good intrinsic soft tissue stability in the knee, a lowconforming bearing design, with a low surface area to be worn is the third low-wearing solution. This is particularly relevant to the partial knee, but is also applicable to tissue preserving the total knee. This lower-conforming design is made possible with the improved stability and mechanical properties of moderately cross-linked XLK polyethylene. It is particularly attractive for use in partial knee solutions where soft tissue stability is maintained.

The principle of a low-conforming low-wear knee was first demonstrated by applying a flat prototype insert to a DePuy Sigma knee with gamma vacuum foil polyethylene. ${ }^{16}$ The worn area of contact is reduced considerably, as shown by the outline of the wear scar in Figure 10. The knee simulator studies with the flat insert and gamma vacuum foil polyethylene showed an extremely low wear rate of $3 \mathrm{~mm}^{3}$ per million cycles, a five-fold reduction compared with a curved insert under high kinematic demand ${ }^{16}$ (Figure 11). This is consistent with a five-fold reduction in surface area being worn.

The principle of low conformity can be readily applied in the partial knee replacement which utilizes XLK polyethylene, because the stability in the knee is delivered through retention of the native soft tissues. In this study, the wear of the Sigma partial knee is compared with the wear of the Oxford conforming mobile unicondylar knee. ${ }^{32}$ The partial knee has a substantially lower wear rate, expressed as the wear rate of a single compartment (Figure 12). ${ }^{32}$

It is possible to compare the wear of a combination of medial and lateral Sigma XLK partial knees (equivalent to a total knee), to the wear of the curved Sigma XLK total knee (Figure 13). ${ }^{32}$ The wear of the lower-conforming partial

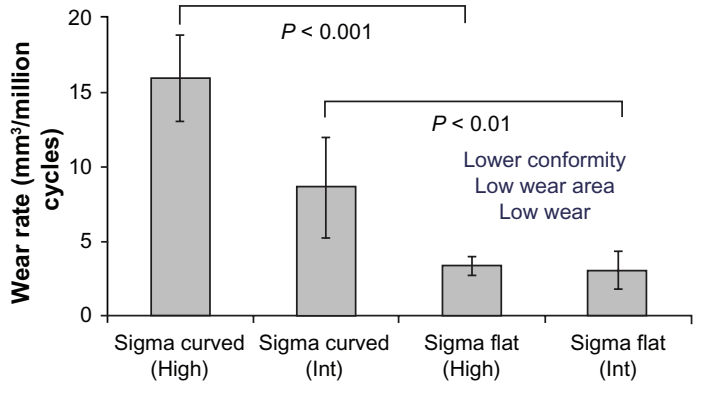

Figure I I Reduction in wear with a prototype flat insert with the Sigma knee.

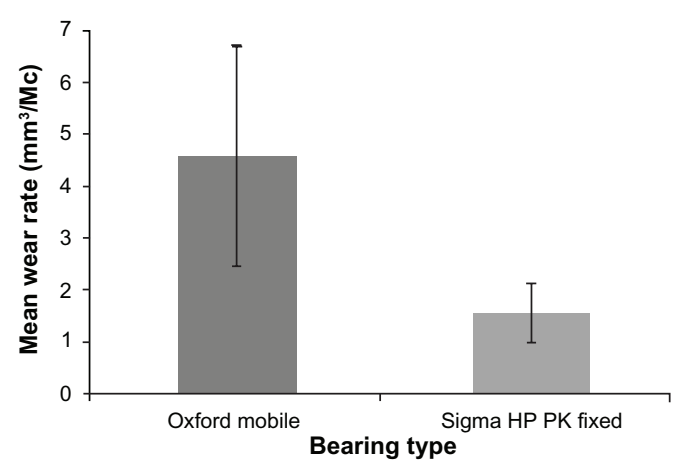

Figure I 2 Reduced wear in DePuy partial knee, compared with conforming Oxford knee.

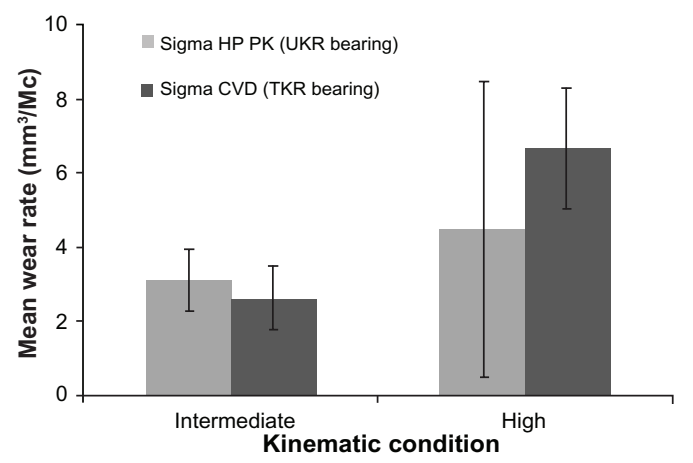

Figure 13 Wear of a combination of medial and lateral sigma XLK partial knee to the wear of the curved Sigma XLK total knee for intermediate and high kinematic conditions. 
knee is less than the XLK curved total knee, but both give low wear rates and a long osteolysis-free lifetime in the total knee. ${ }^{32}$

\section{Summary}

A new wear law has been defined for polyethylene in the knee. ${ }^{16,17,22}$ Wear is reduced by reduced cross-shear, increased cross-linking, and a reduced surface area. This new scientific relationship has been used to create three different and distinctive low-wear solutions in the knee, ie, the rotating platform mobile-bearing knee, the fixed-bearing moderately cross-linked polyethylene knee, and the low-conforming partial knee.

\section{Acknowledgments}

Research funding and support for this research was provided by the Engineering and Physical Sciences Research Council, the Medical Research Council, BBSRC, TSB, Wellcome Trust, ARC, FCRF, EU, NIH, NIHR, and YF.

\section{Disclosure}

All studies reported in this review paper were completed using samples provided by DePuy International, UK. JF, CLB consultant to DePuy International, JF Director of Tissue Regenix, JF Director of BITECIC.

\section{References}

1. Ingham E, Fisher J. Biological reactions to wear debris in total joint replacement. Proceedings of the Institution of Mechanical Engineers Part H: Journal of Engineering in Medicine. 2000;214(H1):21-37.

2. Ingham E, Fisher J. The role of macrophages in osteolysis of total joint replacement. Biomaterials. 2005;26(11):1271-1286.

3. Huddleston J, Scarborough D, Goldvasser D, Freiberg A, Malchau H. 2009 Marshall Urist Young Investigator Award: How often do patients with high-flex total knee arthroplasty use high flexion? Clin Orthop Relat Res. 2009;467(7):1898-1906.

4. Kurtz S, Lau E, Ong K, Zhao K, Kelly M, Bozic K. Future young patient demand for primary and revision joint replacement: national projections from 2010 to 2030. Clin Orthop Relat Res. 2009;467(10): 2606-2612.

5. Medel FJ, Kurtz SM, Parvizi J, Klein GR, Kraay MJ, Rimnac CM. In vivo oxidation contributes to delamination but not pitting in polyethylene components for total knee arthroplasty. J Arthroplasty. 2011;26(5):802-810.

6. Blunn GW, Joshi AB, Minns RJ, et al. Wear in retrieved condylar knee arthroplasties: A comparison of wear in different designs of 280 retrieved condylar knee prostheses. J Arthroplasty. 1997;12(3):281-290.

7. Pradhan NR, Gambhir A, Porter ML. Survivorship analysis of 3234 primary knee arthroplasties implanted over a 26-year period: A study of eight different implant designs. Knee. 2006;13(1):7-11.

8. Dalury DF, Fisher DA, Gonzales RA, Shipps MR, Adams MJ. Minimum five years follow-up of unicompartmental knee arthroplasty in patients age 60 or younger. J Arthroplasty. 2008;25(3):e85-e86.

9. Fisher J, Dowson D, Hamdzah H, Lee HL. The effect of sliding velocity on the friction and wear of UHMWPE for use in total artificial joints. Wear. 1994;175(1-2):219-225.
10. Fisher J, Dowson D. Tribology of total artificial joints. Proceedings of the Institution of Mechanical Engineers. Part H: Journal of Engineering in Medicine. 1991;205(2):73-79.

11. Szivek JA, Anderson PL, Benjamin JB. Average and peak contact stress distribution evaluation of total knee arthroplasties. JArthroplasty. 1996;11(8):952-963.

12. Hooper G, Rothwell A, Frampton C. The low contact stress mobilebearing total knee replacement: a prospective study with a minimum follow-up of ten years. J Bone Joint Surg Br. 2009;91-B(1):58-63.

13. Atwood SA, Van Citters DW, Patten EW, Furmanski J, Ries MD, Pruitt LA. Tradeoffs amongst fatigue, wear, and oxidation resistance of cross-linked ultra-high molecular weight polyethylene. J Mech Behav Biomed Mater. 2011;4(7):1033-1045.

14. Edidin AA, Herr MP, Villarraga ML, Muth J, Yau SS, Kurtz SM. Accelerated aging studies of UHMWPE. I. Effect of resin, processing, and radiation environment on resistance to mechanical degradation. J Biomed Mater Res. 2002;61(2):312-322.

15. Archard JF. Contact and rubbing of flat surfaces. $J$ Appl Phys. 1953;24(8):981-988.

16. Galvin AL, Kang L, Udofia I, et al. Effect of conformity and contact stress on wear in fixed-bearing total knee prostheses. J Biomech. 2009;42(12):1898-1902.

17. Fisher J, Jennings L, Galvin A, Jin Z, Stone M, Ingham E. 2009. Knee Society Presidential Guest Lecture: Polyethylene wear in total knees. Clin Orthop Relat Res. 2009;468(1):12-18.

18. Barbour PSM, Barton DC, Fisher J. The influence of stress conditions on the wear of UHMWPE for total joint replacements. J Mater Sci Mater Med. 1997;8(10):603-611.

19. Kang L, Galvin AL, Fisher J, Jin Z. Enhanced computational prediction of polyethylene wear in hip joints by incorporating cross-shear and contact pressure in additional to load and sliding distance: Effect of head diameter. J Biomech. 2009;42(7):912-918.

20. Kang L, Galvin AL, Brown TD, Fisher J, Jin Z-M. Wear simulation of ultra-high molecular weight polyethylene hip implants by incorporating the effects of cross-shear and contact pressure. Proceedings of the Institution of Mechanical Engineers. Part H: Journal of Engineering in Medicine. 2008;222(7):1049-1064.

21. McEwen HMJ, Barnett PI, Bell CJ, et al. The influence of design, materials and kinematics on the in vitro wear of total knee replacements. J Biomech. 2005;38(2):357-365.

22. Kang L, Galvin AL, Brown TD, Jin Z, Fisher J. Quantification of the effect of cross-shear on the wear of conventional and highly cross-linked UHMWPE. J Biomech. 2008;41(2):340-346.

23. Galvin AL, Tipper JL, Jennings LM, et al. Wear and biological activity of highly crosslinked polyethylene in the hip under low serum protein concentrations. Proc I Mech Eng H. 2007;221(1):1-9.

24. Kurtz SM. The clinical performance of UHMWPE in knee replacements. In: UHMWPE Biomaterials Handbook. 2nd ed. Boston, MA: Academic Press; 2009.

25. Dumbleton JH, Manley MT, Edidin AA. A literature review of the association between wear rate and osteolysis in total hip arthroplasty. J Arthroplasty. 2002;17(5):649-661.

26. Fisher J, McEwen HMJ, Tipper JL, et al. Wear, debris, and biologic activity of cross-linked polyethylene in the knee: benefits and potential concerns. Clin Orthop Relat Res. 2004;428:114-119.

27. Howling GI, Barnett PI, Tipper JL, Stone MH, Fisher J, Ingham E. Quantitative characterization of polyethylene debris isolated from periprosthetic tissue in early failure knee implants and early and late failure Charnley hip implants. J Biomed Mater Res. 2001;58(4): 415-420.

28. Malchau H, Herberts P, Eisler T, Garellick G, Söderman P. The Swedish total hip replacement register. J Bone Joint Surg Am. 2002;84-A Suppl 2:S2-S20.

29. Jennings L, Bell C, Ingham E, Komistek R, Stone M, Fisher J. The influence of femoral condylar lift-off on the wear of artificial knee joints. Proceedings of the Institution of Mechanical Engineers. Part H: Journal of Engineering in Medicine. 2007;221(3):305-314. 
30. Galvin A, Jennings LM, McEwen HM, Fisher J. The influence of tibial tray design on the wear of fixed-bearing total knee replacements. Proceedings of the Institution of Mechanical Engineers. Part H: Journal of Engineering in Medicine. 2008;222(8):1289-1293.

31. Brockett CL, Jennings LM, Hardaker CS, Fisher J. Wear of moderately cross-linked polyethylene fixed bearing knee replacements. Paper presented at the Annual Meeting of the Orthopaedic Research Society, Long Beach, CA, January 13-16, 2011.
32. Brockett CL, Jennings LM, Fisher J. The wear of fixed and mobile bearing unicompartmental knee replacements. Proceedings of the Institution of Mechanical Engineers. Part H: Journal of Engineering in Medicine. 2011;225(5):511-519.

\section{Publish your work in this journal}

Orthopedic Research and Reviews is an international, peer-reviewed, open access journal focusing on the patho-physiology of the musculoskeletal system, trauma, surgery and other corrective interventions to restore mobility and function. Advances in new technologies, materials, techniques and pharmacological agents are particularly welcome. The journal welcomes original research, clinical studies, reviews \& evaluations, expert opinion and commentary, case reports and extended reports. The manuscript management system is completely online and includes a very quick and fair peer-review system, which is all easy to use. Visit http://www.dovepress. com/testimonials.php to read real quotes from published authors.

Submit your manuscript here: http://www.dovepress.com/orthopedic-research-and-reviews-journal 